\title{
BLENDED LEARNING AS THE BASIS FOR SOFTWARE DESIGN
}

\author{
Nadezda Almazova, Anna Rubtsova, Elena Krylova \& Aleksandra Almazova-Ilyina
}

\author{
Peter the Great St. Petersburg Polytechnic University
}
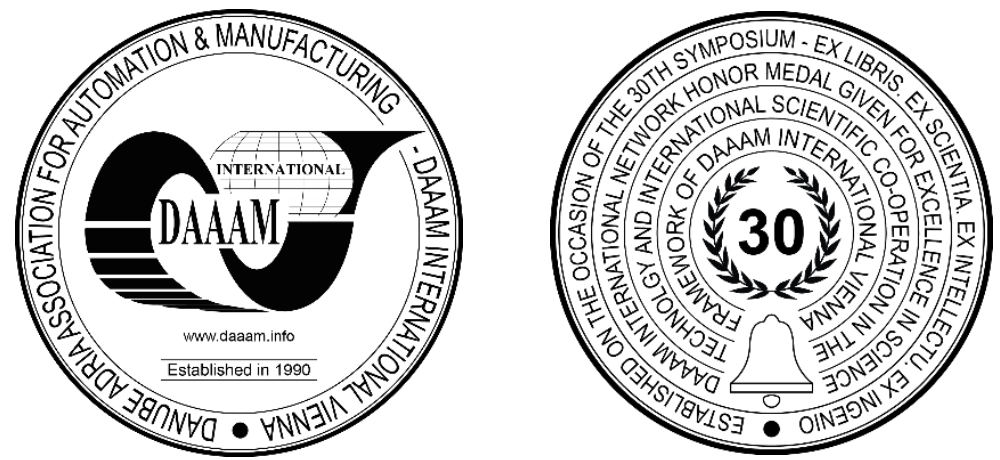

This Publication has to be referred as: Almazova, N[adezhda]; Rubtsova, A[nna]; Krylova, E[lena] \& Almazova-Ilyna, A[leksandra] (2019). Blended Learning as the Basis for Software Design, Proceedings of the 30th DAAAM International Symposium, pp.0806-0813, B. Katalinic (Ed.), Published by DAAAM International, ISBN 978-3-902734-22-8, ISSN 1726-9679, Vienna, Austria

DOI: $10.2507 / 30$ th.daaam.proceedings.112

\begin{abstract}
As the disparity between educational standards and reality outside engineering educational institutions is increasing, it is imperative that new methods of teaching and learning be developed. Tackling this dilemma, blended (or hybrid) learning is a way through which instructors may use various forms of delivery to enhance their students' learning. This paper describes an online application used to bridge teaching English as a foreign language and project oriented programming to IT students. This study was based on an experiment which engaged IT students in developing new software created in purpose to support teaching English as a foreign language to the same students. The paper includes the brief theoretical background dealing with efficiency of blended learning methods; practical part mainly focuses on the description of the application, its development and its implementation in the studying process. The software and the ways it was used during teaching were positively evaluated by students.
\end{abstract}

Keywords: blended learning, programming, application, foreign language, student.

\section{Introduction}

In the modern system of higher technical professional education in Russia, the problem of modification traditional forms of the educational process organization remains significant and relevant. Many factors contribute to this. Modern Russian higher education is based on the learner-centered approach, on the one hand, and widespread informatization, information and communication technologies, social educational networks, professional online communities, MOOC courses, online learning, with open access to educational materials via the Internet, on the other hand. All this learning components require global changes in the educational paradigm, adaptation of educational goals, objectives and principles. Modern society needs specialists with flexibility and adaptability, capable for processing large amount of information, receiving and updating knowledge, constantly improving professional competences. It is obvious that the current system of traditional education in Russia does not allow fully implementing such demands of contemporary society.

The blended learning, combining the strengths of the traditional educational component and the benefits of distance learning technologies, is an effective way to solve the problem of non-compliance of the demands of society and the readiness of the modern higher technical education to satisfy these requests. Particularly relevant, in our opinion, is the use of blended learning for the implementation of the English for specific purposes (ESP) course at a technical university. 
This discipline is today one of the most actual due to its enormous educational potential and communicative significance. The use of blended learning technology in ESP course is due to a shortage of classroom time, an increase in the number of hours devoted to independent work of engineering students. What is more, there is a change in the roles of a student and a teacher in the educational process.

\section{Blended learning approach to engineering education}

\subsection{The concept of Blended Learning}

Traditionally, blended learning refers to a model that integrates the traditional full-time education and electronic / distance learning, and involves replacing parts of traditional training classes with various types of learning interaction in an electronic environment.

Even though the term Blended Learning is frequently used there is some ambiguity about its meaning. C.J. Bonk and C.R. Graham (2006) distinguish three main components of blended learning:

- traditional training with personal contact between students and teachers in the form of classroom studies, the socalled face-to-face instruction;

- independent work of students, which includes various activities (search tasks on the Internet, activities in blogs, chat rooms, wikis, skype, etc.) without the assistance of the teacher (computer-mediated instruction);

- joint e-learning, consisting in performing various tasks in the network, participation in webinars, online conferences, etc. [1]

D.R.Garrison and H. Kanuka (2004) define blended learning as "the thoughtful integration of classroom face-to-face learning experiences with on-line learning experiences". [2]

M. Oliver and K. Trigwell (2005) gave three possible definitions of blended learning:

- The combination of media and tools employed in an e-learning environment.

- The combination of a number of pedagogic approaches, irrespective of the leaning technology used.

- The integrated combination of traditional learning with web-based on-line approaches. [3]

Several benefits of blended learning have been described in the literature, including its flexibility as the most important. (Gedic, Kiraz, Ozden, 2012). [4]

Other benefits of blended learning include the following:

- $\quad$ personalization of the learning process - each student has the opportunity to individually choose the tempo, rhythm and volume of educational material, which contributes to the building of an individual educational route.

- availability - ensuring the independence of the educational process from the time and geographical location of the student; constant access for students to educational resources in real time is implemented.

- effective interaction in the format "student-student", "student-group", "student-teacher" (connectivity) - with the active use of information and communication technologies special conditions are created for interaction and collaboration in the educational community, which in turn develops communicative, informational social and other competencies.

- independent work activation by extra study materials, as well as saving time in the classroom by introducing certain topics for self-study or certain types of tasks to be performed outside the classroom. As a result, selfstudy, self-improvement and research skills are developed, as well as information competence.

- changing the role of the teacher, who ceases to be a "translator" of knowledge, but becomes the coordinator and facilitator, organizing the joint activities of students, and encourages them to independent activity. As a result, the student is transformed from a passive consumer of ready-made knowledge into an active participant in the educational process, his independence and responsibility for the results of his activities increases. The learning process becomes active and inclusive (active learning).

- creativity - students have the opportunity to create an essential individual educational product.

- active use of modern information and communication technologies, which positively affect the motivational component of the student's educational activities.

We agree with N. Almazova (2018) that the training of students based on using information technologies will be improved if the following conditions are fulfilled:

- a significant increase of the level of professional and general humanitarian cooperation between the teachers and the engineering students due to the possibility of organizing joint projects, including telecommunication;

- the expanding the capabilities of traditional libraries and university laboratories through access to electronic libraries and virtual laboratories, to scientific, educational and other cultural and socially significant Internet resources;

- increasing the effectiveness of independent work of students with both the traditional and electronic resources thanks to developed systems of self-monitoring and support of feedback from the teachers. [10]

Researchers in the field of blended learning offer a variety of models and approaches for its implementation in the learning process.

So, C. Twigg (2003) identifies the following four blended learning models: 
- Replacement Model - most of the educational material studied in electronic format. The teacher coordinates the educational process, provides assistance in case of arising difficulties, conducts consultations.

- Supplemental Model - most of the time is devoted to traditional classroom training, which is complemented by working with electronic resources.

- Emporium Model - the model assumes mastering the academic course in the conditions of e-learning on a special website of a department and in specially equipped computer classes.

- Buffet Model -students are given the opportunity to independently combine classroom and electronic classes, according to their educational requirements. [5]

For instance, M.B. Horn and H. Staker (2015) offer the following ways to implement blended learning into the educational process:

- Rotation Model (the Station Rotation, Individual Rotation, Flipped Classroom), where there is a regular alternation of traditional classroom and electronic classes / tasks.

- Flex Model -most of the educational material is acquired remotely, students have the opportunity to get personal advice from the teacher.

- A La Carte Model - the model makes it possible to choose additional e-courses for basic education. Such a model can be useful for students whose interests are beyond the traditional educational program.

- Enriched Virtual Model - at the beginning the course classes are held in the traditional format, in the future, students master the learning material and interact with the teacher remotely [6]

Despite the fact that blended learning is understood and applied differently, most researchers would agree that the main purpose of blended learning is to try to combine the benefits of full-time teaching and e-learning, supported by educational resources. All components of blended learning should be elements of one system that harmoniously interact. E-learning should be a logical continuation of the classroom tasks; must be systematic and continuous throughout the entire period of study; should contribute to the development of the ability to consciously and independently implement and manage personal learning activities. In this case, we can talk about the full realization of the educational potential of information and communication technologies, the use of which involves not only storing and transmitting of educational information, but also enhancing interaction (educational communication) between participants in the educational process, creating a unified educational community. And consequently, there is a rethinking of the role of the teacher and the student. The interaction of the educational process participants and the roles that they usually implement in the blended learning model will be reflected in the following table.

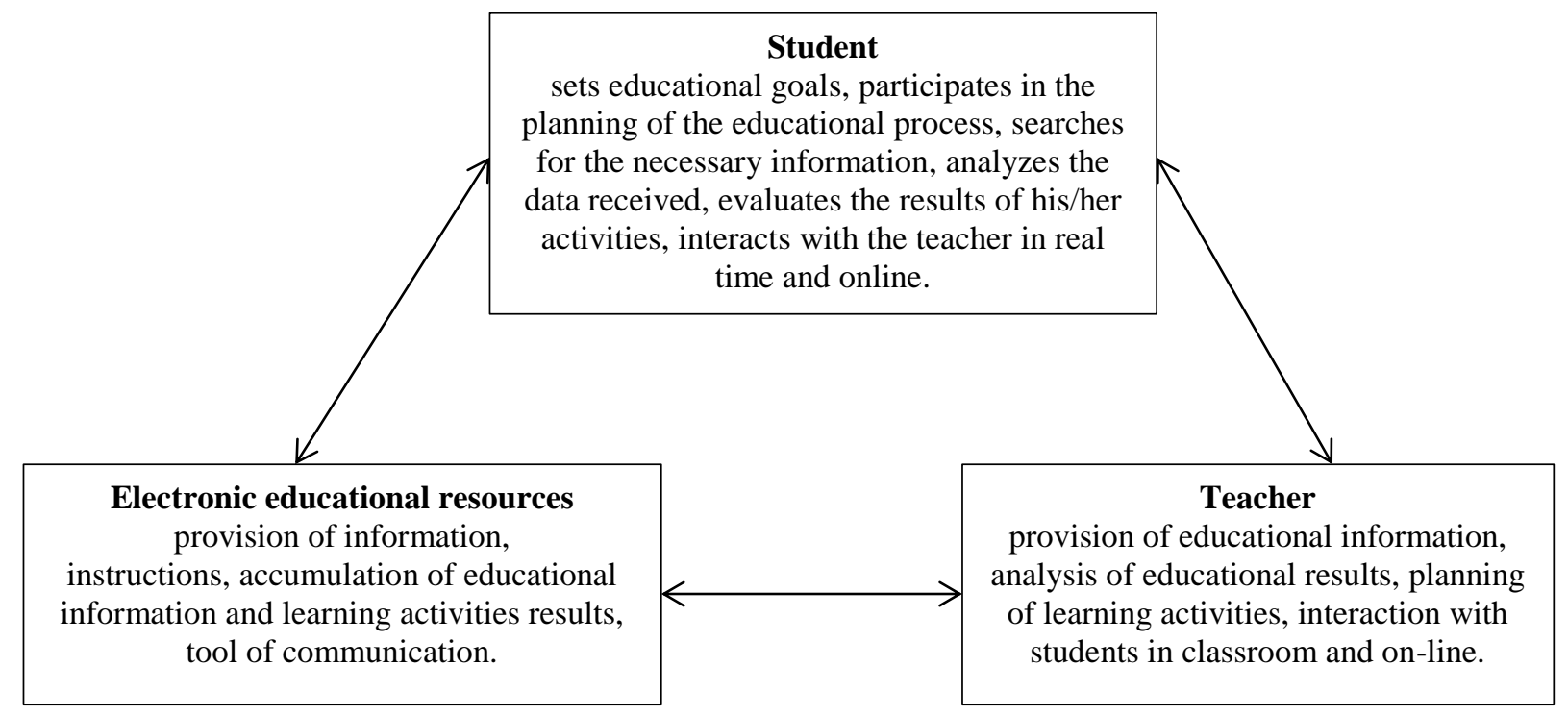

Table 1. Blended Learning subjects and their roles

\subsection{Blended course design}

When planning an effective blended course design, there are three areas that are fundamental. They include: 1) planning course aims; 2) choosing the necessary technologies (educational software, applications, learning management systems) that are responsible for educational content delivery; 3) deciding how to blend face-to-face and on-line components effectively.

Planning course aims: goal-setting, scheduling of the main tasks, content, actions and expected results planning. A. Alammary (2014) underlined that effective blended learning course design focuses on the objectives of the course, not on the technologies. [7] 
Choosing technologies for content delivery: the choice of e-learning tools for distance educational activities depends on the needs of students. It is also necessary to take into account the complexity of the educational material to be independently studied.

Blending face-to-face and on-line components: According to A.Powell (2014), in a blended course, the face-to-face and online components must connect with each other and flow meaningfully from one medium to the next. [8]

All components of blended learning should be elements of one system, interacting harmoniously. In this case, new opportunities for the intensification of the process of classroom and professional training of students are provided on the basis of: effective management of students' cognitive activity; individualized and differentiated learning; maintaining the necessary level of motivation of students; organizing free access to authentic information resources of the Internet, etc.

\subsection{Blended learning course principles}

It is evident that blended learning course design will be effective only in the case of methodically correct organization based on the principles of learning.

Clearly formulated teaching principles - real or presumed patterns and regulations that should guide the learning process - help to decide what learning content to select and how to do it, what materials and techniques to use.

The principle of individualization in vocational education is of particular importance, as it is necessary to take into account personal and age characteristics of students, as well as the majors they specialize in.

The principle of priority of self-study. Independent learning of students is the main type of educational activity involving not only the process of self-studying itself. It also involves self-organization of the learning process within the course by students.

The principle of actualization of learning outcomes. According to this principle the skills, abilities and qualities acquired by students are applied in real-life professional situations within the course.

The principle of collaboration. This principle emphasizes the importance of the joint activities of a teacher and students in planning, implementing, evaluating and correcting the learning process.

The principle of professional orientation of training is fundamental in teaching a foreign language to engineering students. Training in the context of a future profession allows one to form, develop and improve professionally oriented communicative competence to a level sufficient for effective professional communication in a foreign language.

The principle of autonomous learning is associated with an important role of self-studying in modern education. Autonomy means that a student will be able to take control of his or her learning process, evaluate and correct it, as well as be able to independently receive, process and critically interpret information.

The principle of an adequate distribution of learning activities implies such a face-to-face and online components blend, which would correspond to the goals and objectives of the course.

The principle of interactivity implies feedback and an active form of interaction between the subjects of the educational process both in the classroom, and in the process of self-studying of course materials.

\section{The process of creation and implementation of blended learning software}

In this paper, new learning software for English for specific purposes course for prospective IT-specialists was designed using the above described principles and the main issues of blended learning course design. The primary objective of this project is to synchronize the educational opportunities of different subjects taught to perspective ITspecialists. That is why the students were offered to take part in developing a new educational application.

As a result, learning is no longer a formal transfer of knowledge from a teacher to students, but, on the contrary, creates conditions under which students have the opportunity to acquire knowledge and form their own and put it into practice, while there is a mutual cyclic determination of all subjects of learning, their mutual formation, development and design.

\subsection{Applying blended learning principles to course design and learning software creation}

In our study a training course English for specific purposes for future IT specialists, as well as an electronic application to it were designed on the basis of the above described characteristics of blended course design. 
The first step was to focus on the aims of the course and the academic results of the students that can be achieved by the end of the course. According to J. Hofmann (2006) [9] when designing a blended learning course one should focus on the objectives of the course rather than the technologies that can be used. In our study we somewhat deviated from the traditional design pattern of a blended learning course. In can be explained by the fact that the primary objective of the course is not only to develop a foreign language communicative competence of future IT specialists, but also to develop programming and algorithmic reasoning skills to students. That is why the students were invited to participate in the development of software for learning a foreign language from the standpoint of blended learning. Taking part in developing a new application, students had a chance to produce solutions for programming problems.

After the aims were determined and new software was designed, the question of content delivery was raised. The content of each topic was carefully examined. For each topic of the course an appropriate format of content delivery (faceto-face or online) was chosen. Complicated questions that seemed not suitable for students' self-studying were decided to be delivered through traditional face-to-face educational practice. All the other topics were covered online. The electronic component of the blended course contained not only theoretical material. The students were offered some engagement activities and assignments, aimed at self-compiling the material studied and being a logical continuation of the classroom learning process: drawing up flowcharts, writing a thematic glossary, preparing presentations, writing essays, articles, work in a blog, the implementation of educational and research projects. Such learning activities are aimed at developing the reflexive and evaluative skills of engineering students.

\subsection{Blended learning software from a programming perspective}

The developed application is a system which is built using Java EE stack of technology and deployed on Java EE compatible Application Server. From the architecture point of view the system is a multi-tier application which includes presentation, business logic integration and resource tier. The students took part in the implementation of the presentation tier.

\section{Presentation tier}

Template mechanism is used to generate JSP pages to improve scalability and flexibility to customize the screens. Different screens can be generated by passing parameters in the template JSP file. At runtime the template JSP is invoked by the Front Controller component. The mechanism was designed to support future enhancements in the screen. All the users' requests are handled by a single Web Controller (the Front Controller pattern - FacesServlet class). The Front Controller forwards the request to an appropriate Command Handler with the help resource and access mapping information stored in the form of an XML file (fases-config.xml). Command Handler handles user interactions for a specific use case and co-ordinates use case related interactions with the user. The Command Handlers do not perform "business logic". Instead they use Session Facade pattern as the Business provider to the Application Server services. The Command Handlers do not produce any User output. Instead, they call views to create HTML type of a stream that is returned to the user. Views are implemented as JSPs. Session Fasade's are implemented as a Stateless Session Bean.

\section{Business tier}

Business logic tier includes all domain logic of application. There are several Stateless Session Beans that serve as an interface for Backing Bean of presentation tier. Stateless Beans provide transaction management and good scalability if the number of nodes is increased. For session management support the application includes Stateful Session Bean for Customer Cart implementation. Also, Business logic tier includes Message Driven Bean which listens to messages from external Inventory systems and saves them in database. To encapsulate the complexity of Session Beans and provide coarse-grained service access layer the application includes several Session Facades. These are actually Stateless Beans with simple coarse-grained interface for Backing Beans of presentation tier.

\section{Resource tier}

Relational database management system is used to store the persistent data (like order, customer and so on). To manage database the JPA technology is used. Also Repository pattern is included into the system to encapsulate the set of objects persisted in a data store and the operations performed over them, providing a more object-oriented view of the persistence layer.

\section{Integration tier}

There are two external systems which are integrated into the solution - Merchant Bank and International Shippers. Both of these systems expose Web Services to operate. So Stateless Beans from Business tier are the clients of these Web Services.

Fig. 1 shows the deployment schema on customers' servers. 


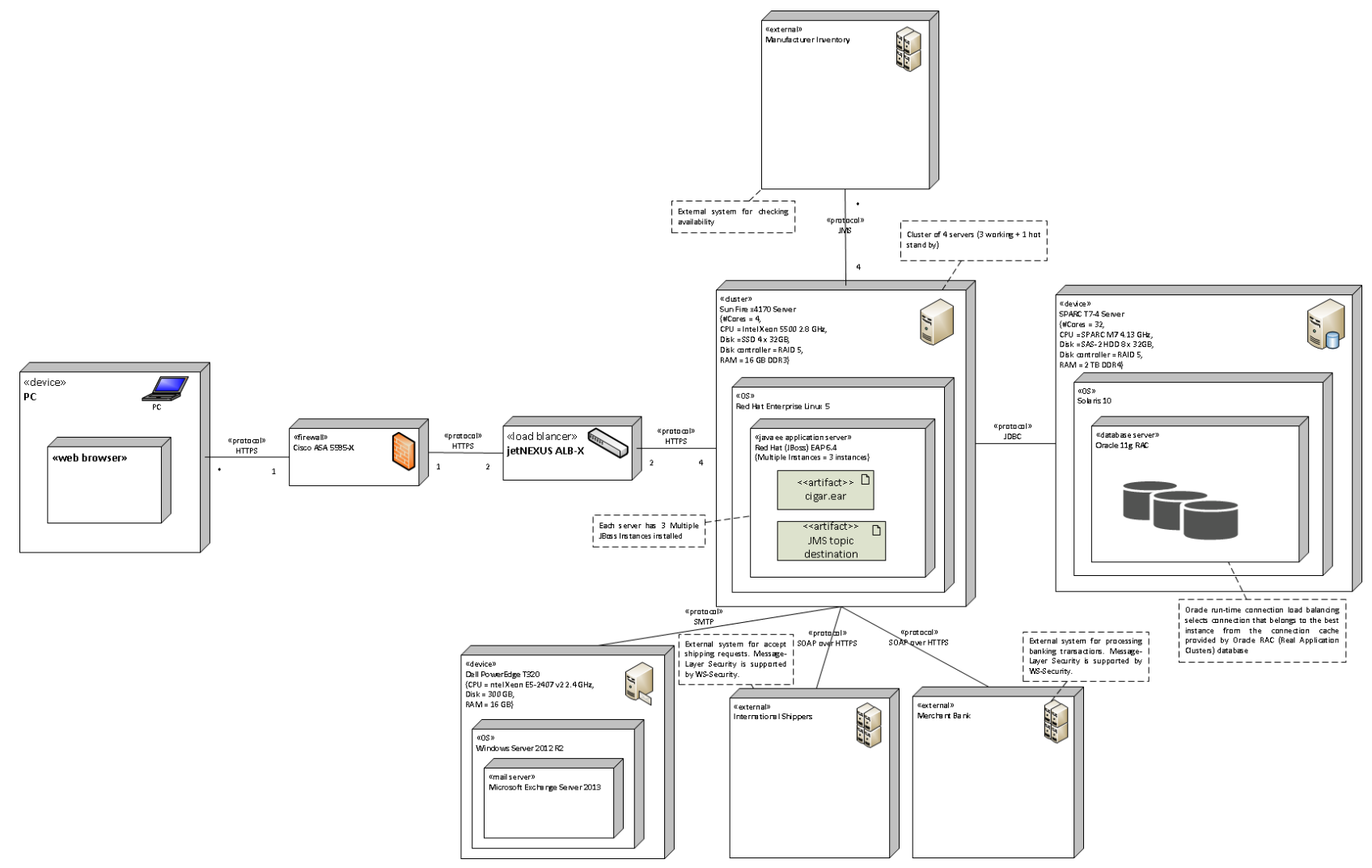

Fig.1. Deployment diagram

\subsection{Blended learning software description and parameters}

Development of blended learning software was carried out at two stages - design and implementation stages.

The technical stage is devoted to the development of a software resource, which is a web application that every student registered in it has access to. The web application consists of client and server parts, thereby implementing the clientserver technology. A modern cross-platform solution based on the Java EE (Enterprise Edition) technology stack was chosen to develop a web application. On the server side there are databases that contain various texts, audio recordings, grammar tasks, as well as a variety of test tasks. The client part is implemented on the basis of the teaching module and the module for students. Through the teaching module the monitoring of the progress of students' self-studying process is organized. The module for students consists of Units, and the access to each subsequent lesson is opened only if the previous one is completed. Fig. 2 presents the introductory page developed with the help of prospective IT specialists.

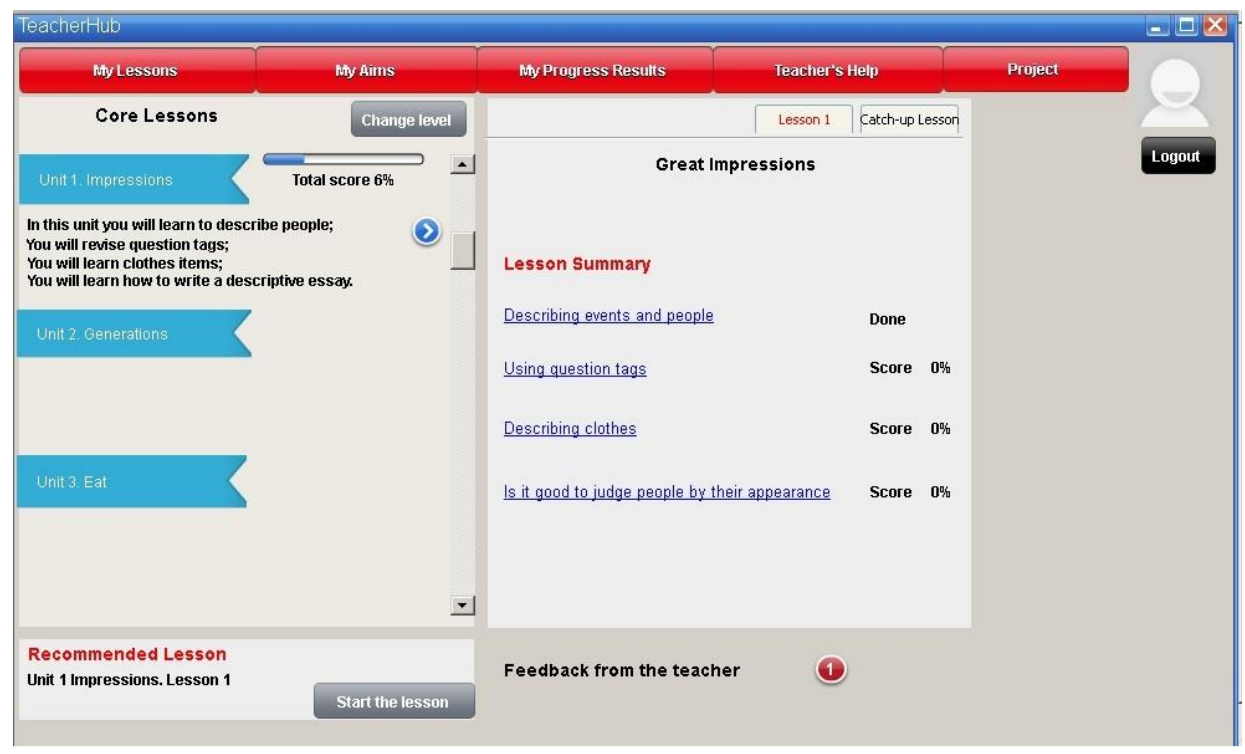

Fig.2. Introductory page 
The home page presents the tabs My Lessons, My Aims, My Progress Results, Teacher's Help, Project.

When you select the My Lessons tab, a list of Units for self-studying is available. Each Unit consists of two parts. The first is obligatory. The number of completed tasks is tracked by the Total Score indicator.

In the orientation part (Unit Summary) there is a brief description of the lesson presented, its goals are described and the activities that will be encountered are listed. The student sees the structure of the entire lesson, namely all the tasks to be completed. The informational part is directly related to the thematic content of each lesson - these are professionallyoriented texts, grammar exercises, listening tasks, writing and speaking skills development tasks, etc. The diagnostic part presents the results of the students' assignments.

The results can be seen, and on the basis of these data, one can adjust and correct his or her self-studying process. The reflective part contains materials (questionnaires, questions, etc.) aimed at the development of students' reflexive abilities, and therefore, contributing to their understanding of how their goals coincided with the results obtained.

The start page also displays a message indicator from the teacher - Feedback from the Teacher. Communication with the teacher is carried out synchronously and asynchronously through the tab Teacher's Help (instant messaging service, e-mail).

When the My Progress Results tab is selected, the student can get acquainted with the results of the completed tasks. The above mentioned reflexive questionnaires and resources that develop the skills of self-education activities are also found in this tab and are offered to students at different stages of their self-studying process.

In the Project tab, each student receives recommendations for the implementation of an individual creative task.

In our opinion, the My Aims tab is of particular interest. It is a section independently filled by students with personally meaningful educational content in accordance with a given topic when performing a set of special exercises. These tasks involve a sequence of educational actions that correlate, in our opinion, with the real activity of an engineering specialist when working with professionally oriented foreign language sources: search and initial study of information, detailed analysis of selected information in linguistic and professional aspects, application of the obtained professionally important information in productive speech forms.

\section{Experiment}

The experiment was conducted in the framework of ESP course for IT-students at Herzen State Pedagogical University and Peter the Great St. Petersburg Polytechnic University and involved 25 bachelor students. The main aim of the course is to improve engineering students' communicative competence in English and to focus on the practical real life-based application of their programming skills.

In order to determine the developmental dynamics of engineering students' educational progress some preexperimental and post-experimental diagnostic tests were conducted.

For the students' learning progress diagnostics we have determined the activities and tools which allow to estimate the degree of their communicative competence development:

- the results of tests during the term

- the results of the final test

- the students' performance in the classroom (taking part in discussions, projects, asking questions and so on)

- online work in the developed application (the frequency of using the application, the results of the tasks done, communication with the peers and the teacher)

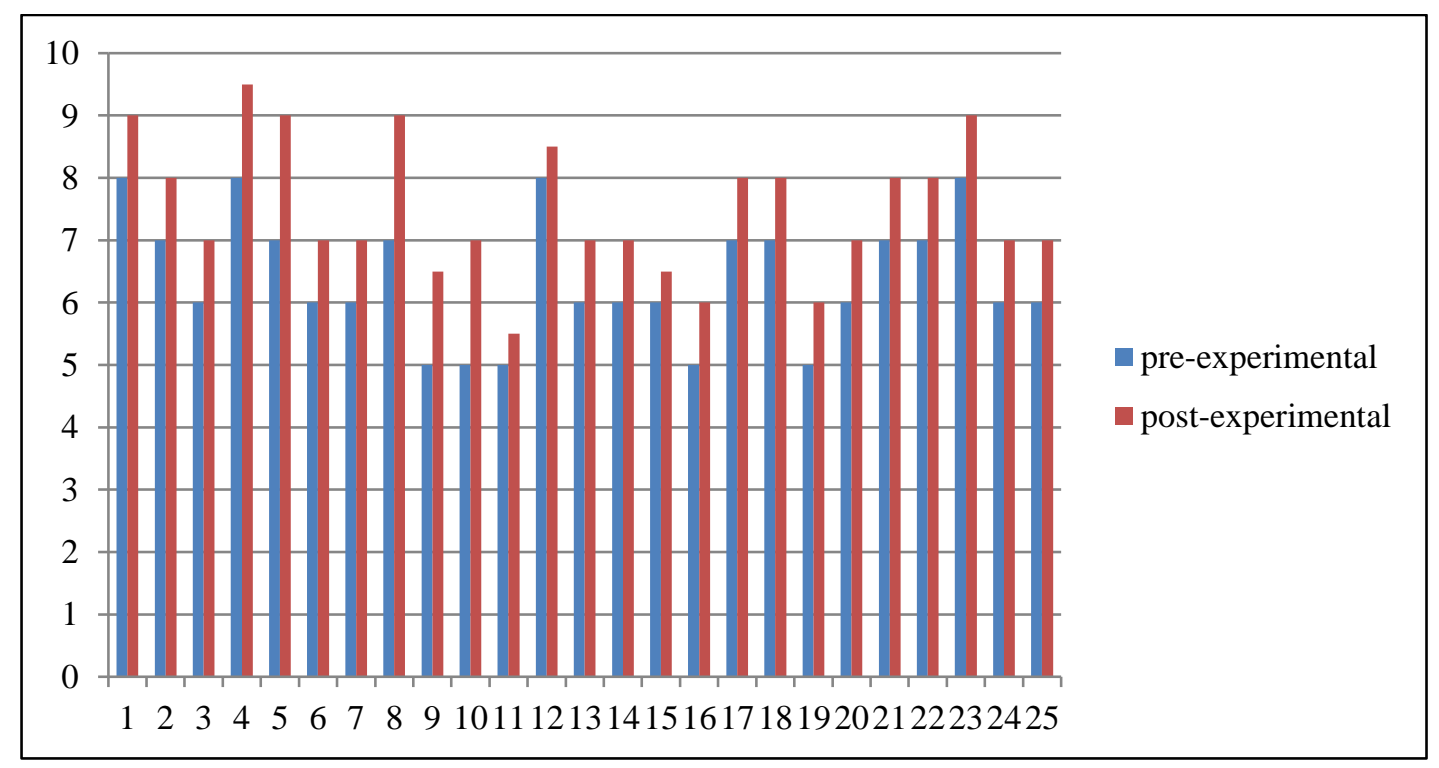

Fig.3. Engineering students' educational progress 
In Fig. 3 (showing the comparison of pre-experimental and post-experimental results) vertical numbers 0-10 mean levels of communicative competence; horizontal numbers 1-25 are the code numbers of students. At the end of the course students were e-mailed a survey with close-ended and open-ended questions concerning the advantages and disadvantages of the suggested course. The survey was voluntary and anonymous. 24 students out of 25 took part in the survey. The questions were the following ones:

- Did you take part in the creation of the software?

- What were the benefits (if any) of taking part in software design?

- Did you use the created software?

- What were the benefits and challenges of the using the created software for online studying?

- Was the use of the crated software beneficial for your in-class performance?

- Do you have any comments on how the course was structured and taught?

The survey results were analyzed and the following conclusions were made:

- According to the survey 23 students took part in the developing a new learning application.

- Most students focused on the benefits of having an opportunity to practice their programming skills while learning English for specific purposes in an engaging and motivating way.

- All the students used the created software and highlighted its beneficial influence on their learning: flexibility, opportunity to work at their own pace and to choose educational content, online engagement and communication with peers and the teacher, opportunity to study the topics that will be discussed in class beforehand.

- Some challenges were mentioned: lack of self-discipline and poor time management when working online.

- Most students were ready to continue their work with the developed software both from learning and programming point of view.

\section{Conclusions}

The paper presented newly created educational software used for teaching English for specific purposes to engineering students in an engaging and motivating way. The data obtained in the course of the experiment, allow us to conclude that the proposed technology optimizes the learning process. Interactivity and personalization of education, various types of pedagogical influence, increase in the amount of absorbed material due to the active students' self-studying process, work with a large number of authentic electronic resources, direct participation of students in the development of the necessary electronic tools suggest that the described technology is able to bring engineering students' foreign language training to a new effective level. As with any research study, there are some limitations to our approach. The number of student who took part in the project is relatively small. Students' reactions and performance in the course may have differed under different online educational software or a different blended learning design. A bigger number of students taking part in the project might have led to additional results and suggestions. Future work will be oriented on further development of the newly created application.

\section{References}

[1] Bonk, C.J., \& Graham, C.R. (2006). The handbook of blended learning: global perspectives, local designs, Pfeiffer publishing, ISBN 978-0-7879-7758-0, San Francisco, CA.

[2] Garrison, D.R., \& Kanuka, H. (2004). Blended learning: Uncovering its transformative potential in higher education. Internet and Higher Education, Vol. 7, No. 2, pp. 95-105, ISSN 1096-7516.

[3] Oliver, M., \& Trigwell, K. (2005). Can 'blended learning' be redeemed? E-learning and digital media, Vol. 2, No. 1, pp. 17-26, ISSN 1741-8887.

[4] Gedik, N., Kiraz, E., \& Ozden, M. (2012). The optimum blend: Affordances and challenges of blended learning for students. Turkish Online Journal of Qualitative Inquiry, Vol. 3, No. 3, pp. 102-117, ISSN 1309-6591.

[5] Horn, M.B., \& Staker, H. (2015). Blended: Using Disruptive Innovation to Improve Schools, Jossey-Bass, ISBN 978-1118955154, San Francisco, CA, USA.

[6] Twigg, C.A. (2003). Improving Learning and Reducing Costs: New Models for Online Learning, EDUCAUSE Review, Vol. 38, No. 5, pp. 29-38, ISSN 1527-6619.

[7] Alammary, A., Sheard, J., \& Caebone, A. (2014). Blended learning in higher education: Three different design approaches. Australasian Journal of Educational Technology, Vol. 30, No. 4, pp. 440-454, DOI 10.14724/ajet.693.

[8] Powel, A., Rabbitt, B., \& Kennedy, K. (2014). iNACOL blended learning teacher competency framework, Available from: https://www.inacol.org/wp-content/uploads/2015/02/iNACOL-Blended-Learning-Teacher-CompetencyFramework.pdf, Accessed: 2019-03-26.

[9] Hofman, J. (2006). Why blended learning has not yet fulfilled its promises: Answers to those questions that keep you up at night, In: The handbook of blended learning: Global perspectives, local designed, C.J., \& Graham, C.R., (Eds.), pp. 27-40, Pfeiffer publishing, ISBN 978-0-7879-7758-0, San Francisco, CA.

[10] Almazova, N., Barinova, D., Ipatov, O. (2018). Forming of information culture with tools of electronic didactic materials. Proceedings of the 29th DAAAM International Symposium, pp.0587-0593, B. Katalinic (Ed.), Published by DAAAM International, Published by DAAAM International, ISBN 978-3-902734-20-4, ISSN 1726-9679, Vienna, Austria. 